Escuela de Ciencias Sociales y Humanidades, UNED, C.R. URL: http://investiga.uned.ac.cr/revistas/index.php/espiga/index ISSN: 1409-4002 - e-ISSN: 2215-454X Doi: http://dx.doi.org/10.22458/re.v17i34.1840

\title{
La normativa peruana en materia de tráfico de migrantes a la luz del Derecho Internacional: ¿Hacia una protección de los derechos de las personas migrantes?
}

«Si la delincuencia atraviesa las fronteras, lo mismo ha de hacer la acción de la ley»*.

«La migración, aún (sic) la irregular (mejor dicho, especialmente la irregular) es una decisión extrema que se dirige, precisamente a intentar ejercer de manera efectiva el derecho a la vida en condiciones dignas, así como el derecho a la libre circulación y el derecho a salir del país»**.

\section{Cécile Blouin***}

iD https://orcid.org/ 0000-0002-4499-1737

Recibido: 12 de julio, 2017 • Aceptado: 29 de noviembre, 2017

Formato de citación según APA

Blouin, C. (2017). La normativa peruana en materia de tráfico de migrantes a la luz del Derecho Internacional: ¿Hacia una protección de los derechos de las personas migrantes?. Revista Espiga 16(34), 215-230. Doi: http://dx.doi.org/10.22458/re.v17i34.1840

Formato de citación según Chicago-Deusto

Blouin, Cécile. «La normativa peruana en materia de tráfico de migrantes a la luz del Derecho Internacional: ¿Hacia una protección de los derechos de las personas migrantes?». Revista Espiga, 16, n. ${ }^{\circ} 34$ (julio-diciembre, 2017): 215-230. Doi: http://dx.doi. org/10.22458/re.v17i34.1840

* Kofi Annan, ex secretario General de la Organización de las Naciones Unidas. Prefacio a la Convención de las Naciones Unidas contra la Delincuencia Organizada transnacional, 2000.

** Ceriani Pablo, «Control migratorio europeo en territorio africano: la omisión del carácter extraterritorial de las obligaciones de derechos humanos», SUR Revista Internacional de Derechos Humanos. Año 6, n. ${ }^{\circ}$ 10, Sao Paolo, junio de 2009, 196.

*** Licenciada en Derecho y Ciencias Políticas por la Universidad de Versailles Saint-Quentin-en Yvelines (Francia). Máster en Derecho de la Unión Europea por la Universidad Carlos III de Madrid (España). Máster en Derecho, mención estudios bilingües de los derechos europeos: especialización en Derecho español-Derecho francés por la Universidad de París X Nanterre (Francia). Investigadora sénior del Instituto de Democracia y Derechos Humanos de la Pontificia Universidad Católica del Perú y profesora de la Maestría en Derechos Humanos de la misma casa de estudios. Pontificia Universidad Católica del Perú. Perú.cblouin@pucp.edu.pe 


\section{RESUMEN}

El presente artículo propone analizar la normativa peruana en materia de tráfico de migrantes desde una perspectiva de derechos humanos. Debido a las múltiples aristas del tema y las obligaciones del Derecho Internacional, el Estado ha adoptado de manera progresiva un conjunto de normas para atender dicha problemática. Este marco normativo enfrenta una serie de retos, en primer lugar, responde a una realidad poco conocida, debido a la falta de datos confiables sobre el tráfico; en segundo lugar, se superpone en cada momento con la trata de personas lo que resulta en una invisibilización del tráfico; y en tercer lugar, no llega a entender el tráfico como una problemática de derechos humanos para las personas migrantes.

Palabras claves: tráfico de migrantes, derechos humanos, vulnerabilidad, normativa migratoria.

\section{Introducción}

El cruce de fronteras en condiciones de inseguridad mediante traficantes siempre ha existido; sin embargo, la dependencia de las personas migrantes a los traficantes ha ido aumentando con el paso de los años ${ }^{1}$. Ello se puede explicar por distintos motivos, tales como el incremento de controles migratorios en distintas partes del mundo, las políticas restrictivas de asilo, así como la expansión de medios de transporte internacionales ${ }^{2}$. Las vulneraciones a los derechos humanos de las personas migrantes en sus desplazamientos por vías irregulares han sido puestas a la luz en los últimos años, es así que la Organización Internacional para las Migraciones calculó que 5400 migrantes han perdido la vida en 2015 cruzando fronteras y otros 3100 murieron en los primeros cinco meses de $2016^{3}$. En general, la realidad del tráfico de migrantes es poco conocida e investigada debido a la misma naturaleza de este tránsito marcado por la irregularidad y la vulnerabilidad que impide a las víctimas reclamar por sus derechos. Además, la utilización de pasos fronterizos no autorizados por parte de los migrantes mediante los traficantes que operan, dificulta la identificación del delito y los perfiles de sus víctimas ${ }^{4}$.

La idea extendida sobre la temática es que el tráfico sería esencialmente vinculado al crimen organizado, lo cual de acuerdo con varios autores, no está probado ${ }^{5}$. Esta mirada

1. Van Liempt Ilse y Sersli, Stephanie State, «Responses and Migrant Experiences with Human Smuggling: A Reality Check», Antipode 45, n. ${ }^{\circ} 4$ (2013): 1029-1046.

2. Juan Carlos, Murillo, «Migración extra continental en América Latina: algunas tendencias y consideraciones de protección internacional», 2010. En: http://www.acnur.org/t3/fileadmin/Documentos/ BDL/2010/7720.pdf?view=1 (Para el análisis del caso de la frontera México-Estados Unidos, se recomienda revisar el artículo de Simón Pedro Izcara Palacios «La transformacón del coyotaje en el contexto de políticas migratorias restrictivas», Estudios Sociales 46, 2014.)

3. Organización Internacional para las Migraciones, Fatal Journeys Volume 2 Identification and Tracing of Dead and Missing Migrants, 2016. Acceso: 12 febrero, 2018, https://publications.iom.int/system/files/ fataljourneys_vol2.pdf

Adicionalmente ver: Amnistía Internacional, El costo humano de la fortaleza europea. Violaciones de Derechos Humanos cometidas en las fronteras de Europa contra personas migrantes y refugiadas, 2014. Acceso: 12 febrero, 2018, https://www.amnesty.org/es/documents/EUR05/001/2014/es/

4. Isabel Berganza, Setién, Ciudadanía migrante. Rutas, costos y dinámicas de los flujos mixtos en tránsito por Perú (Lima: UARM, 2016), 60-69. 
que ha sido tomada por el Derecho, no ha permitido observar a las personas migrantes como las verdaderas víctimas del tráfico, sino que los esfuerzos se han centrado en criminalizar la conducta, por lo que es necesario comprender el tráfico y sus consecuencias más allá de la mirada delictiva y centrarse en la perspectiva de la persona migrante.

Para ello, en este trabajo se busca abordar el estado de la cuestión de la normativa peruana en la materia y su adecuación al Derecho Internacional. Por esto, se divide el trabajo en dos partes. La primera analiza las obligaciones internacionales de los Estados en materia de tráfico de migrantes mediante el análisis de las obligaciones derivadas del derecho penal transnacional, así como del derecho internacional de los derechos humanos (DIDH) y el Derecho Internacional de los Refugiados (DIR). La segunda examina la normativa peruana en la materia desde una mirada internacional, buscando evaluar si el Estado ha establecido un marco para proteger a las personas migrantes objeto de tráfico.

\section{Las obligaciones de los Estados en materia de tráfico de migrantes}

El Derecho Internacional, con la adopción de la Convención de las Naciones Unidas contra la Delincuencia Organizada transnacional (en adelante la Convención) y sus protocolos, en especial el Protocolo contra el tráfico ilícito de migrantes por tierra, mar y aire (en adelante el Protocolo $)^{6}$, plantea el marco jurídico especializado en materia de tráfico de migrantes.

El proceso de Viena que llevó a la adopción de estos instrumentos es el primer esfuerzo del Derecho para dotarse de un instrumento jurídico para luchar contra el crimen transnacional organizado ${ }^{7}$. Durante las negociaciones las organizaciones de la sociedad civil han sido muy participativas sobre las disposiciones del Protocolo contra la trata de personas, en especial mujeres y niñas (en adelante Protocolo de Palermo); mientras que menos interés se generó alrededor del tema de tráfico, lo que se tradujo en una menor participación de organizaciones de la sociedad civil (Gallagher: 37). Si bien se verá que el Protocolo incluye obligaciones para los Estados en materia de derechos humanos, el enfoque detrás de este instrumento es el vínculo que existe entre los intereses de seguridad nacional basado en la soberanía de los Estados con la existencia de redes criminales transnacionales de tráfico de migrantes ${ }^{8}$. Aunque se verá que el delito de tráfico ilícito de migrantes no requiere la participación de un grupo criminal organizado, esta conexión está enraizada en el instrumento jurídico a pesar de la falta de evidencias ya mencionadas en la introducción.

5. Ilse van Liempt y Stephanie Sersli: State Responses..., 1035.

6. La Convención de las Naciones Unidas contra la Delincuencia Organizada Transnacional, el Protocolo para prevenir, reprimir y sancionar la trata de personas, especialmente mujeres y niños, que complementa la Convención de las Naciones contra la Delincuencia Organizada Transnacional y el Protocolo contra el tráfico ilícito de migrantes por tierra, mar y aire, que complementa la Convención de las Naciones Unidas contra la Delincuencia Organizada Transnacional, fueron aprobados por la resolución 55/25 de la Asamblea General de las Naciones Unidas el 15 de noviembre de 2000. El protocolo contra la fabricación y el tráfico ilícitos de armas de fuego, sus piezas y componentes y municiones, que complementa la Convención de las Naciones Unidas contra la Delincuencia Organizada Transnacional, fue aprobado por la resolución 55/255 de 31 de mayo de 2001.

7. Anne T. Gallagher y Fiona David, The international Law..., 36.

8. Ibíd., 36 . 
Adicionalmente, es importante subrayar que no solamente la Convención y el Protocolo obligan a los Estados en la materia, sino que deben tomarse en cuenta las disposiciones del Derecho Internacional de los Derechos Humanos (en adelante, DIDH) y del Derecho Internacional de los Refugiados (en adelante, DIR). En este sentido, primero se define qué se entiende por tráfico de migrantes (a) para luego detallar las obligaciones de los Estados a raíz del Protocolo (b) y, finalmente se presentan las obligaciones desde el DIDH y DIR más relevantes para la materia de este artículo (c).

\section{La definición del tráfico ilícito de migrantes de acuerdo con el Protocolo}

En cuanto a la definición del tráfico ilícito de migrantes ${ }^{9}$, el Protocolo contra el tráfico ilícito de migrantes por tierra, mar y aire que complementa la Convención de las $\mathrm{Na}$ ciones Unidas contra la Delincuencia Organizada transnacional del año 2000, contempla en el artículo 3 que «la facilitación de la entrada ilegal de una persona en un Estado Parte del cual dicha persona no sea nacional o residente permanente con el fin de obtener, directa o indirectamente, un beneficio financiero u otro beneficio de orden material».

Son tres los elementos sin los cuales no se puede hablar de tráfico de migrantes: 1 . El carácter necesariamente transfronterizo de la movilidad o traslado de las personas, objeto de tráfico ilícito de migrantes; 2 . El ingreso irregular a un país de destino, es decir, sin respetar las normas de control migratorio; 3. El propósito subjetivo de obtener lucro o una ventaja patrimonial con el traslado de personas. Es necesario diferenciar este concepto del de migración irregular, por un lado, y, por otro lado, de trata de personas.

En relación con el tema del vínculo del tráfico de migrantes con la migración irregular, es necesario señalar que la migración irregular abarca un abanico de situaciones mucho más amplio que el tráfico de migrantes; es decir, existen personas en situación irregular que no han usado los servicios de una persona o un grupo para el cruce de fronteras, sino que no cuenten con la documentación requerida por las normas del Estado de residencia. En ese sentido, se puede afirmar que «todas las personas objeto de tráfico son migrantes en situación irregular, pero no todos los migrantes en situación irregular han sido objeto de tráfico ilícito de migrantes» ${ }^{10}$.

En relación con el tema del vínculo del tráfico de migrantes con la trata de personas; es preciso mencionar que cuando se prepararon los borradores de la Convención y sus protocolos, el tráfico y la trata fueron primero pensados como problemática similar que debía ser prevista en el mismo instrumento normativo ${ }^{11}$. Si bien se ha optado por adoptar dos instrumentos distintos, su estructura es muy similar y ha llevado a una confusión entre estas dos problemáticas. La trata de personas se puede definir como «la captación, el traslado o la recepción de una persona, por medio de la subyugación de su voluntad,

9. A lo largo del artículo se usa la terminología de tráfico de migrantes considerando que ningún tráfico puede ser licito.

10. Mac Gillivray, Jeremy y otros (coordinadores). «Manual de capacitación para operadores de justicia durante la investigación y el proceso penal en casos de trata de personas». Lima: IDEHPUCP/OIM, 2017, 66.

11. Anne T. Gallagher y Fiona David, The international Law..., 66. 
con el fin de someterla a una serie de situaciones de explotación, totalmente contrarias a la dignidad humana y a los valores esenciales de una sociedad democrática ${ }^{12}$. Para que se configure la trata de personas es necesario contar con un medio tal como el engaño, abuso de una situación de una vulnerabilidad, así como que exista la finalidad de explotación. En el caso del tráfico de migrantes, la finalidad prevista es el cruce de fronteras y el consentimiento existe en el sentido en el cual la persona migrante acepta este contrato con el traficante. Ello no ha impedido que existan situaciones en las cuales los delitos se confundan. Se han observado dos principales: la primera cuando el tráfico de migrantes es en realidad una situación de trata en la cual el traficante busca desde el principio someter a explotación a la persona migrante; y la segunda, cuando el tráfico de migrantes se transforma en trata de personas a la llegada al país de destino por su situación de indefensión ${ }^{13}$.

En cuanto al objetivo del Protocolo, es importante observar, desde ahora, que busca perseguir la acción del tráfico de migrantes en sí, no las consecuencias de este. Es decir, el foco de atención está en la persona o los grupos de personas que se dedican a generar beneficios mediante la facilitación del cruce irregular de fronteras de otras personas y no en la persona migrante que usa sus servicios ${ }^{14}$.

Finalmente, se debe tener claro el tratamiento jurídico hacia la persona migrante de acuerdo con el Protocolo. Este instrumento eligió usar la expresión «objeto del delito» y no «víctima del delito» por el hecho de que la persona migrante ha dado su consentimiento para el tráfico de migrantes ${ }^{15}$. Solo se considerará víctima si ha sufrido otros delitos durante el tráfico (secuestros, situaciones de violencia, maltrato, entre otros). Ello tiene impactos importante en la protección que se dará a las personas migrantes, ya que la Convención reconoce derechos específicos a las víctimas de crímenes organizados, los cuales solo serán aplicados a las personas migrantes que han sido objeto de tráfico de migrantes cuando hayan sido víctimas de otros delitos ${ }^{16}$.

\section{Obligaciones planteadas por el Protocolo}

El Protocolo establece cuatro grandes grupos de obligaciones para el Estado: la primera vinculada a la prevención del delito, la segunda referida a la penalización del tráfico de migrantes y sus formas agravadas, la tercera vinculada a la promoción de la

12. Blanco Cristina y Marinelli Chiara, «Víctimas de trata de personas versus migrantes en situación irregular. Retos y lineamientos para la atención y protección de las víctimas de trata de personas extranjeras en el Perú», Revista Derecho PUCP, n. ${ }^{\circ} 78$ (2017): 173-198. Acceso: 12 de febrero, 2018, http://revistas.pucp. edu.pe/index.php/derechopucp/article/view/18645/18979, 177.

13. Cristina Blanco y Chiara Marinelli, Victimas de trata..., 179.

14. Anne T. Gallagher y Fiona David, The international Law..., 44.

15. UNODC, Ley modelo..., 21.

16. Anne. T. Gallagher y Fiona David, The international Law..., 48, artículo 25. «Asistencia y protección a las víctimas 1. Cada Estado Parte adoptará medidas apropiadas dentro de sus posibilidades para prestar asistencia y protección a las víctimas de los delitos comprendidos en la presente Convención, en particular en casos de amenaza de represalia o intimidación. 30 2. Cada Estado Parte establecerá procedimientos adecuados que permitan a las víctimas de los delitos comprendidos en la presente Convención obtener indemnización y restitución. 3. Cada Estado Parte permitirá, con sujeción a su derecho interno, que se presenten y examinen las opiniones y preocupaciones de las víctimas en las etapas apropiadas de las actuaciones penales contra los delincuentes sin que ello menoscabe los derechos de la defensa». 
cooperación entre Estados; y la última vinculada a la protección de los derechos de las personas migrantes ${ }^{17}$. Por su propósito, este trabajo se centra en la última.

Al principio de los trabajos preparatorios del Protocolo, las obligaciones vinculadas a la asistencia y protección no figuraban; ello refuerza la idea ya planteada de que el instrumento viene del derecho penal transnacional y que está pensado para la persecución penal del traficante, entendido como parte de un grupo delictivo organizado. Sin embargo, como explica Gallagher, a medida que se estaba preparando el texto del Protocolo, algunas voces expresaron la preocupación por las personas migrantes y su posible criminalización mediante el Protocolo, así como la necesidad de proteger a las personas solicitantes de la condición de refugiado de acuerdo con la Convención sobre el Estatuto de Refugiado del año 1951. Las diversas agencias de la ONU remarcaron la importancia de garantizar el derecho al asilo mediante la inclusión de disposiciones en el Protocolo ${ }^{18}$. Es necesario entender que muchas personas solicitantes de asilo están usando los servicios de traficantes debido a las dificultades propias de su condición (huida del país de origen por temor de persecución), así como el aumento de controles migratorios.

Ahora bien ¿Cuáles son las medidas de asistencia y protección que establece el Protocolo?

En primer lugar, el artículo 5 del Protocolo ha establecido el principio de no criminalización: la persona migrante objeto de tráfico no puede ser procesada penalmente por el delito de tráfico de migrantes. Ello implica que ninguna persona migrante puede ser objeto de sanción penal por encontrarse en situación de tráfico de migrantes.

En segundo lugar, el Protocolo contempla algunas obligaciones vinculadas a la protección y asistencia de las personas migrantes, las cuales deben adaptarse a las necesidades específicas de los niños y niñas, así como de las mujeres (artículo 16 inciso 4); estas se desarrollan a continuación:

1. Adoptar medidas para preservar y proteger los derechos de las personas objeto de tráfico de migrantes, conforme a las normas aplicables del derecho internacional, en particular, el derecho a la vida y el derecho a no ser sometido a tortura o a otras penas o tratos crueles, inhumanos o degradantes;

2. Adoptar medidas apropiadas para otorgar a los migrantes protección adecuada contra toda violencia que puedan infligirles personas o grupos por el hecho de haber sido objeto de las conductas enunciadas en el artículo 6 del presente Protocolo;

3. Prestar asistencia apropiada a los migrantes cuya vida o seguridad se haya puesto en peligro como consecuencia de haber sido objeto de las conductas enunciadas en el artículo 6 del presente Protocolo;

4. Garantizar, en el caso de detención a personas migrantes el cumplimiento de las obligaciones contraídas con arreglo a la Convención de Viena sobre Relaciones

17. El artículo 2 del Protocolo establece que «El propósito del presente Protocolo es prevenir y combatir el tráfico ilícito de migrantes, así como promover la cooperación entre los Estados Parte con ese fin, protegiendo al mismo tiempo los derechos de los migrantes objeto de dicho tráfico».

18. Anne T. Gallagher y Fiona David, The international Law..., 63. 
Consulares, cuando proceda, incluida la de informar sin demora a la persona afectada sobre las disposiciones relativas a la notificación del personal consular y a la comunicación con dicho personal.

Adicionalmente, el artículo 18 del Protocolo regula el retorno de las personas migrantes y el artículo 19 recuerda las obligaciones derivadas del DIDH y DIR ${ }^{19}$. Tal como lo afirma Gallagher, los Estados no podrán, en la implementación del Protocolo, incumplir las obligaciones del DIDH o DIR ${ }^{20}$. Tomando en cuenta ello, es necesario realizar un breve repaso de las obligaciones de DIDH y DIR por su especial relevancia en materia de tráfico de migrantes.

\section{Obligaciones derivadas del DIDH y DIR}

Para los fines de este artículo no se abordarán todas las obligaciones del DIDH y DIR sino las más relevantes para el propósito de este documento. Antes de entrar a detallar estas obligaciones, es necesario recordar que las personas migrantes objeto de tráfico pueden ser personas solicitantes de asilo: niños, niñas, en algunos casos no acompañadas o separados; apátridas; trabajadores migratorios; víctimas de trata; etcétera. Ello implica entender que según su condición las personas objeto de tráfico de migrantes cuentan con una serie de instrumentos que reconocen su condición y las obligaciones específicas que derivan de ella ${ }^{21}$.

En relación con los proceso de expulsión, la obligación de no devolución implica que ninguna persona puede ser devuelta a un país del cual hay razones fundadas por creer que sufrirá vulneraciones a su derecho a la vida, libertad o integridad ${ }^{22}$. Este principio es una norma de ius cogen y, en ese sentido, es inderogable.

En relación con las personas solicitantes de la condición de refugiado, es importante señalar que los Estados deben garantizarles el acceso a los procedimientos de determinación de la condición de refugiado, lo que se ha llamado el no rechazo en fronteras.

19. «1. Nada de lo dispuesto en el presente Protocolo afectará a los demás derechos, obligaciones y responsabilidades de los Estados y las personas con arreglo al derecho internacional, incluidos el derecho internacional humanitario y la normativa internacional de derechos humanos $\mathrm{y}$, en particular, cuando sean aplicables, la Convención sobre el Estatuto de los Refugiados de 1951 y su Protocolo de 1967, así como el principio de non-refoulement consagrado en dichos instrumentos. 2. Las medidas previstas en el presente Protocolo se interpretarán y aplicarán de forma que no sea discriminatoria para las personas por el hecho de ser objeto de las conductas enunciadas en el artículo 6 del presente Protocolo. La interpretación y aplicación de esas medidas estarán en consonancia con los principios de no discriminación internacionalmente reconocidos».

20. Anne T. Gallagher y Fiona David, The international Law..., 65.

21. En el caso de niños y niñas los Estados están obligados por la Convención sobre Derechos del Niño, en el caso de trabajadores migratorios debemos referirnos a la Convención Internacional sobre la Protección de los Derechos de Todos los Trabajadores Migratorios y de sus Familiares, entre otras.

22. Ver, entre otros, artículo 33 de la Convención sobre el Estatuto de Refugiado: «Ningún Estado Contratante podrá, por expulsión o devolución, poner en modo alguno a un refugiado en las fronteras de los territorios donde su vida o su libertad peligre por causa de su raza, religión, nacionalidad, pertenencia a determinado grupo social, o de sus opiniones políticas.»; artículo 2 de la Convención contra la Tortura: «1. Ningún Estado Parte procederá a la expulsión, devolución o extradición de una persona a otro Estado cuando haya razones fundadas para creer que estaría en peligro de ser sometida a tortura». 
Ello implica que las personas objeto de tráfico de migrantes que necesitan protección internacional, deben ser admitidas en el territorio hasta que se termine el examen de su solicitud de reconocimiento ${ }^{23}$.

En cuanto al tema de expulsiones, tema sumamente sensible en materia de control migratorio, se prohíbe las expulsiones colectivas; es decir, los Estados no pueden expulsar a un grupo de personas migrantes sin un examen individual de cada situación ${ }^{24}$. Ello toma especial relevancia en caso del tráfico de migrantes, ya que muchas veces las personas migrantes llegan en grupo y, en tal caso, queda claro que el Estado deberá examinar cada situación migratoria por separada.

Asimismo, la Convención Internacional sobre la Protección de los Derechos de Todos los Trabajadores Migratorios y de sus Familiares (en adelante CMW) ha establecido una serie de estándares: decisión de expulsión por una autoridad designada por ley, decisión por escrito y motivada en un idioma que puede ser entendido por la persona migrante, derecho a la defensa y revisión de la decisión, suspensión de la decisión mientras dure la revisión, entre los elementos principales ${ }^{25}$.

Finalmente, en cuanto al tema de detención por motivos migratorios, la CMW reconoce a todos los trabajadores migratorios, independientemente de su situación, el derecho a no ser sometidos, individual ni colectivamente, a detención o prisión arbitrarias y a no ser privados de su libertad, salvo por los motivos y de conformidad con los procedimientos que la ley establezca ${ }^{26}$. El Comité de Protección de Derechos de Todos los Trabajadores Migratorios y de sus Familiares en su Observación General $\mathrm{N}^{\circ} 2$, ha reiterado que el cruce de fronteras de manera irregular no es un delito ${ }^{27}$ y que la detención migratoria es una medida de carácter excepcional que debe ser necesaria e idónea, así como proporcional con el fin perseguido ${ }^{28}$.

Luego de abordar el marco internacional desde la Convención y el Protocolo, así como las obligaciones derivadas del DIR y DIDH, sigue el análisis de la normativa peruana sobre tráfico de migrantes.

\section{La normativa peruana: ¿Hacia una protección de las personas migrantes en situación de tráfico?}

En este acápite, se busca analizar la normativa peruana a la luz de lo desarrollado anteriormente sobre el marco internacional en materia de tráfico de migrantes. Para ello,

23. Oficina del Alto Comisionado de las Naciones Unidas para los Refugiados Manual de Procedimientos y Criterios para Determinar La Condición de Refugiado en virtud de la Convención de 1951 y el Protocolo de 1967 sobre el Estatuto de los Refugiados, párrafo 192. Acceso: 12 de febrero, 2018, http://www.acnur. org/t3/fileadmin/Documentos/BDL/2011/7575.pdf

24. Ver, entre otros, el artículo 22.9 de la Convención Americana de Derechos Humanos.

25. Otros estándares están vinculados al pago de salarios.

26. Convención Internacional sobre la Protección de los Derechos de Todos los Trabajadores Migratorios y de sus Familiares, artículo 16.

27. Ello de acuerdo con el artículo del Protocolo que como vimos plantea el principio de no criminalización de la entrada irregular de una persona migrante.

28. Comité de Protección de Derechos de Todos los Trabajadores Migratorios y de sus Familiares. Observación General 2 sobre los derechos de los trabajadores migratorios en situación irregular y de sus familiares, 2003. 
primero es importante partir de la ausencia sobre la situación del tráfico de migrantes en el país dificulta la construcción de una política migratoria (a), para luego presentar la evolución de la normativa peruana que ha ido desde un enfoque penal hacia migratorio (b), para luego examinar las complejidades y contradicciones de la normativa desde una perspectiva de derechos humanos (c).

\section{Ausencia de datos sobre tráfico de migrantes en el país}

Como se presentó en la introducción, en general es muy difícil contar con datos sobre la realidad del tráfico en el mundo. En el caso peruano, donde aún existen pocos estudios en la materia, es poca la información sistematizada-académica y oficial-que se tiene sobre este problema. Es decir, no se cuenta con un mapeo claro de las rutas, las personas migrantes involucradas y sus perfiles, así como el perfil de los traficantes, etcétera. En cuanto a casos judicializados, se han registrado 209 procesos de tráfico ilícito de migrantes entre 2012 y 2015 , de acuerdo con el Poder Judicial, frente a 120 denuncias penales en el mismo periodo, de acuerdo con el registro del Ministerio Público ${ }^{29}$.

En el 2016 se publicó una investigación centrada en las zonas fronterizas de Perú con Ecuador, Brasil, Bolivia y Chile, así como Cusco, Lima y Callao. Como se analiza en la investigación, las rutas y las nacionalidades de los migrantes en condición irregular son cambiantes, ya que buscan eludir cualquier control migratorio y dependen de las medidas que toma el Estado en la materia ${ }^{30}$. Se describe que el tránsito por Perú parte de la frontera con Ecuador para llegar a Brasil (personas haitianas y senegaleses) o Chile (personas colombianas y dominicanas), a la excepción de la migración cubana, de tránsito que busca llegar a Lima para emprender su ruta hacia el norte del continente ${ }^{31}$.

Un estudio sobre la migración haitiana permitió dar cuenta de una migración predominantemente masculina que llega al Perú provenientes de Haití o de la República Dominicana, pueden ser jóvenes, que buscan apoyar a sus familias, o adultos que forman parte de un proyecto familiar. La investigación no ha podido identificar una gran red de traficantes, sino más bien redes locales que actúan en coordinación con funcionarios públicos ${ }^{32}$.

En relación con la frontera Perú-Chile se han identificado casos de tráfico de migrantes que son captados en la misma ciudad de Tacna y otros casos en los cuales las personas migrantes, en especial de Haití o República Dominica, han contratado los servicios de la red desde el país de origen para llegar a Chile. En cuanto a las rutas del tráfico de migrantes, en esta zona se ha reportado tanto el uso de rutas por pasos habilitados, evadiendo

29. Información compartida por la Defensoría del Pueblo en una reunión bilateral en marzo del 2017.

30. Isabel Berganza, Setién. Ciudadanía migrante ..., 79.

31. Isabel Berganza, Setién. Ciudadanía migrante ..., 88.

32. Tania Vasquez, Erika Busse, y Lorena, Izaguirre, «Migración de población haitiana a Perú y su tránsito hacia Brasil desde el año 2010». Acceso: 12 de febrero, 2018, http://repositorio.iep.org.pe/bitstream/ IEP/11/1/Vasquez_Migraciondepoblacion.pdf, 71 . 
el control con participación de funcionarios públicos, así como el tránsito por pasos inhabilitados mediante rutas sumamente peligrosas en los cuales hay campos minados ${ }^{33}$.

\section{Evolución de la normativa peruana: del enfoque penal a migratorio}

Los esfuerzos del Estado peruano en la materia empiezan con la ratificación del Protocolo ${ }^{34}$.

El segundo hito lo marca la adopción de la Ley n. ${ }^{\circ} 28950$, Ley contra la Trata de Personas y el Tráfico Ilícito de Migrantes, que tipifica el delito de tráfico ilícito de migrantes de la siguiente manera: «El que promueve, favorece, financia o facilita la entrada o salida ilegal del país de otra persona, con el fin de obtener directa o indirectamente, lucro o cualquier otro beneficio para sí o para terceros, será reprimido con pena privativa de libertad no menor de cuatro ni mayor de seis años.» (Artículo 303 A del Código Penal). Es importante señalar que siguiendo la normativa internacional, el Estado peruano optó por tipificar tanto la trata de personas como el tráfico de migrantes en un único instrumento.

Esta ley fue reglamentada, en un primer momento, por el Decreto supremo n. ${ }^{\circ} 007-$ 2008-IN, el cual plantea disposiciones generales para abarcar la trata de personas y el tráfico de migrantes de manera conjunta, dividiendo las obligaciones del Estado entre prevención, persecución y atención y protección. No se establece ninguna medida específica para las personas migrantes que han sido objeto de tráfico. Este reglamento fue derogado por el Decreto Supremo n. ${ }^{\circ}$ 001-2016-IN, que aprueba el Reglamento de la Ley $\mathrm{n} .^{\circ} 28950^{35}$. Este Reglamento se distingue del anterior en el sentido que prevé una serie de disposiciones en cuanto a la protección de las personas objeto de tráfico de migrantes, siguiendo lo planteado por el Protocolo estudiado anteriormente.

33. Luna Chávez, Gonzalo, «Tráfico ilícito de migrantes en frontera Tacna-Arica: causas, modalidades de captación, traslado, rutas y accidentes frecuentes». Ponencia realizada en el V Congreso Latinoamericano sobre Trata y Tráfico realizado en Lima, 14 de julio de 2017.

34. El Estado peruano ratificó la convención y sus protocolos el día 23 enero de 2002. Acceso: 12 de febrero, 2018, https://treaties.un.org/Pages/Treaties.aspx?id=18\&subid=A\&clang=_en

35. Decreto Supremo n. ${ }^{\circ} 001-2016-I N$ que aprueba el Reglamento de la Ley n. ${ }^{\circ} 28950$, Ley contra la Trata de Personas y el Tráfico Ilícito de Migrantes, y crea la Comisión Multisectorial de naturaleza permanente contra la Trata de Personas y el Tráfico Ilícito de Migrantes. 
TABLA 1

Medidas de protección y asistencia previstas en Decreto Supremo n. ${ }^{\circ}$ 001-2016-IN que aprueba el Reglamento de la Ley n. ${ }^{\circ} 28950$

Principio de no criminalización. 48

Brindar seguridad y trato humano.

Proteger contra la violencia.

Proteger la identidad y privacidad.

Brindar información clara y comprensible sobre la situación en la que se encuentra, su situación legal y migratoria y los medios de protección y asistencia que se le pueden brindar, en un idioma o medio que comprenda acorde a su edad.

Informar sobre el derecho de ponerse en contacto con representantes diplomáticos o consulares de su nacionalidad.

Asistencia a personas migrantes, en especial a las víctimas y a los niños y niñas y mujeres embarazadas.

Asistencia médica de emergencia o urgencia.

Respetar el interés superior del niño.

En caso de niños, niñas o adolescentes no acompañados, debe adoptarse las medidas de protección que correspondan para garantizar su integridad física y psicológica; tomar las medidas necesarias para determinar su identidad y nacionalidad y realizar las acciones para localizar a su familia con el fin de facilitar la reunificación familiar, cuando ello redunde en beneficio del interés superior de la niña, niño o adolescente.

Prohibición de la detención por motivo de tráfico y establecer que la detención sólo puede darse por otros hechos en base a mandatos judiciales y de acuerdo a ley.

El proceso de repatriación debe darse de forma pronta respetando las disposiciones del derecho internacional, en especial DIDH y DIR.

Hasta este momento, la normativa peruana seguía el esquema internacional, centrado en la persecución al traficante, por lo que dejaba de lado a la persona migrante objeto de este tráfico.

Finalmente, en 2017 se adoptó el Decreto Legislativo de Migraciones y su reglamento $^{36}$ que reconoce a las personas víctima de tráfico de migrantes como grupo vulnerable (artículo 11) y crean la calidad migratoria "humanitaria", competencia del Ministerio de Relaciones Exteriores (artículo 29 k.) y "especial” competencia de la Superintendencia Nacional de Migraciones (artículo 29 c.). Estas nuevas categorías constituyen un avance que permite dar una solución migratoria a una diversidad de grupos vulnerables tales como personas víctimas de trata de personas, niñez no acompañada, apátrida, personas que huyen de su territorio por razones vinculadas a desastres naturales y medioambientales y también personas en situación de tráfico de migrantes. Sin embargo, como se ha reportado en el Informe Alternativo al Comité de Protección de los Derechos de Todos

36. La Ley fue aprobada por Decreto Legislativo n. ${ }^{\circ} 1350$, publicado el 7 de enero de 2017 en el Diario Oficial el Peruano y el Reglamento por Decreto Supremo n. ${ }^{\circ} 007-2017-I N$ publicado el 27 de marzo de 2017 en el Diario Oficial el Peruano. 
los Trabajadores Migratorios, la existencia de dos calidades migratorias para situaciones vulnerables resulta confusa ${ }^{37}$. En la práctica la calidad «especial» ya se está implementando en caso de extrema vulnerabilidad ${ }^{38}$, mientras que en la «humanitaria» no se ha previsto el procedimiento para el acceso a tal calidad migratoria, lo que resulta en la actualidad en una falta de aplicación de esta norma ${ }^{39}$.

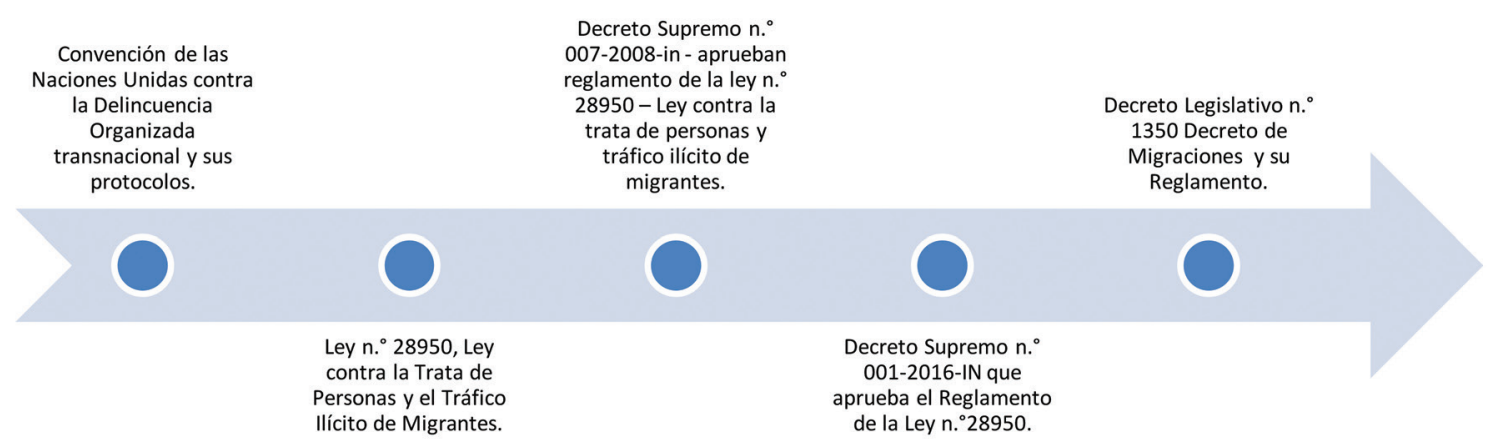

Figura 1. Evolución del marco normativo sobre tráfico de migrantes.

Dificultades y retos para atender a las personas migrantes objeto de tráfico desde una perspectiva de derechos humanos

En esta parte, es necesario visibilizar algunas dificultades y preocupaciones en cuanto al cumplimiento por parte del Estado peruano de sus obligaciones en materia de tráfico.

Lo primero es que la superposición de la trata de personas y tráfico de migrantes en todos los instrumentos mencionados ha generado que el foco del tema se haya centrado en la trata de personas debido a su carácter de grave violación a los derechos humanos. Ello ha generado una invisibilización del tema de tráfico de migrantes. Como se puede observar, en materia de trata se ha desarrollado un número importante de protocolos y guías que buscan viabilizar las obligaciones del Estado en cuanto a persecución, prevención y sobre todo atención y protección a las víctimas ${ }^{40}$. No es propósito de este artículo analizar los resultados de esta política, sin embargo sí se debe señalar que en materia de tráfico no se ha desarrollado ningún tipo de instrumento de política pública que permita

37. Instituto de Democracia y Derechos Humanos de la Pontificia Universidad Católica del Perú(IDEHPUCP), Informe alternativo sobre Perú al Comité de protección de los Derechos de todos los Trabajadores Migratorios y de sus Familiares. 2017. Acceso: 13 de diciembre, 2017, http://cdn01.pucp.education/idehpucp/wp-content/uploads/2017/09/11234252/11-09-final-informe-alternativo-al-comite-de-protecciontrabajadores-migratorios.pdf, 12.

38. Migraciones Comunicado, MIGRACIONES entregó carné de extranjería a ciudadanos chilenos heridos en accidente del cerro San Cristóbal. Acceso: 11 de diciembre, 2017, https://www.migraciones.gob. $\mathrm{pe} / \mathrm{p}=7604$

39. De acuerdo con la información mandada por el Ministerio de Relaciones Exteriores de Perú en respuesta a un pedido de acceso a la información pública con fecha del 26 de mayo de 2017, el Ministerio está trabajando en una reglamentación de la calidad migratoria humanitaria.

40. Para un resumen de los instrumentos, ver Blanco y Marinelli, Victimas de trata..., 191-194. 
atender a la problemática. Por lo tanto, solo se cuenta con las normativas presentadas en el acápite anterior, lo que no permite contar con herramientas para atender de manera adecuada a las personas migrantes.

Lo segundo es referido al tratamiento que se da a la persona migrante en situación de tráfico de migrantes, se encuentra una contradicción entre el Decreto Legislativo de Migraciones, el cual, a diferencia del Reglamento de la Ley de Trata y Tráfico, se refiere a las personas migrantes como víctimas del tráfico y no objeto. Esta diferencia terminológica refleja el problema complejo, ya abordado en este artículo, de entender cuál es el escenario de las personas en situación de tráfico y quién determina el tratamiento que se les dará según su posición de víctima u objeto. De acuerdo con un análisis pro persona, se entiende que cualquier persona migrante que haya recurrido a los servicios de un traficante podría acogerse a la normativa migratoria sin necesidad de haber sido reconocido como víctima de un delito en el transcurso del viaje por el Ministerio Público. Es urgente conocer la reglamentación de la calidad migratoria humanitaria y los requisitos para el acceso a la calidad migratoria especial para atender a este grupo de personas, apostando porque se haga desde una perspectiva de derechos humanos.

Finalmente, y como tercer punto de preocupación, se deben señalar las contradicciones entre el Reglamento de la Ley de Trata y Tráfico, que no permite la detención de las personas migrantes en situación de tráfico, con la posibilidad planteada en el Reglamento de Migraciones de retener a las personas migrantes. En efecto, el Reglamento, excediendo su campo de competencia, establece en sus artículos 200.4 y 212.2, que la retención podrá darse, por un lado, para la identificación de la persona migrante y determinación de su condición y, por otro lado, para ejecutar la sanción de salida obligatoria o expulsión. Estas formas de privación de la libertad no están establecidas por ley y tampoco se establecen su duración y revisión por una autoridad judicial ${ }^{41}$. En este caso, la normativa no es acorde a los estándares planteados en el acápite anterior, en especial de acuerdo con la Convención sobre trabajadores migratorios y del Comité. A la fecha no existe información oficial sobre casos de detención contra personas migrantes que hayan sido objeto de tráfico. Sin embargo de acuerdo con lo reportado al Comité de Protección de los Derechos de Todos los Trabajadores Migratorios y de sus Familiares, son 21 personas que han sido retenidas en el Aeropuerto Internacional Jorge Chávez entre 2015 y el primer semestre $2017^{42}$.

\section{Conclusiones}

Como se ha visto a lo largo de este artículo, la problemática del tráfico de migrantes es compleja y poco conocida. Compleja porque abarca no solamente el delito, sino sus consecuencias vinculadas con la problemática de la migración que impone una mirada más integral y protectora en la materia. Ello resulta difícil porque los esfuerzos internacionales se han centrado en la persecución del delito más que en la búsqueda de entender y reducir las causas estructurales, así como adoptar medidas para la protección de

41. IDEHPUCP Informe Alternativo, 20 .

42. IDEHPUCP Informe Alternativo, 16. 
quiénes son los verdaderos afectados, las personas migrantes. Cuando se habla de una problemática poco conocida, se hace hincapié en la falta de información existente en la materia, lo que impide construir una política pública integral en esta materia. El caso peruano no escapa a esta caracterización. Primero, la falta de datos sobre la realidad del tráfico en el país impide el desarrollo de políticas en el tema. Segundo, si bien existe además de la normativa penal una respuesta migratoria preliminar mediante la calidad humanitaria, urge reglamentarla, ya que por ahora, en la práctica, las personas migrantes objeto o víctimas del delito no cuentan con ningún tipo de medida migratoria. En tercer lugar es preocupante que algunos mecanismos de control migratorio, en especial, la retención migratoria, contradiga los estándares del derecho internacional y pueda impactar de manera desproporcional a las personas migrantes que han sido víctimas de tráfico, por su especial situación de vulnerabilidad.

\title{
ABSTRACT \\ Peruvian legislation on migrant smuggling under international law: Towards the protection of the rights of migrants?
}

\begin{abstract}
This article aims to analyze Peruvian legislation regarding migrant smuggling under a human rights perspective. Given the many aspects involved and the obligations under international law, the State has progressively adopted a set of regulations for this problem. This legal framework faces a series of challenges; first of all, it is a little known reality due to the lack of trustworthy data. Secondly, it is superposed with human trafficking, which results in invisibility; thirdly, it does not consider smuggling as human rights problematic for migrants.
\end{abstract}

Key words: migrant smuggling, human rights, vulnerability, migration law.

\section{RÉSUMÉ}

La réglementation péruvienne en matière de trafic de migrants à la lumière du Droit International: Vers une protection des droits des personnes migrantes?

Cet article propose d'analyser la réglementation péruvienne en matière de trafic de migrants dans une perspective des droits de l'homme. Dû aux différents angles de la problématique et aux obligations du Droit International, l'État a adopté de manière progressive un ensemble de normes afin de traiter ce sujet. Ce cadre normatif doit faire face à une série de défies ; d'abord répondre à une réalité peu connue à cause du manque de données fiables sur le trafic. Deuxièmement, il doit rendre visible ce problème qui est souvent confondu avec la traite des êtres humains. Et troisièmement, comprendre le trafic comme une problématique des droits humains pour les personnes migrantes.

Mots clès: mots clés: trafic de migrants, droits de l'homme, vulnérabilité, réglementation d'immigration.

\section{Bibliografía}

«Amnistía Internacional. El costo humano de la fortaleza europea. Violaciones de derechos humanos cometidas en las fronteras de Europa contra personas migrantes y refugiadas 2014». Acceso:1 10 de julio, 2017. https://www.amnesty.org/es/documents/EUR05/001/2014/es/ 
Berganza, Setién Isabel. Ciudadanía migrante. Rutas, costos y dinámicas de los flujos mixtos en tránsito por Perú. Lima: UARM , 2016.

Blanco, Cristina y Marinelli Chiara. «Víctimas de trata de personas versus migrantes en situación irregular. Retos y lineamientos para la atención y protección de las víctimas de trata de personas extranjeras en el Perú». Revista Derecho PUCP, n. ${ }^{\circ}$ 78, 2017: 173-198. Acceso: 20 de junio, 2017. http://revistas.pucp.edu. pe/index.php/derechopucp/article/view/18645/18979

Ceriani Cernadas, Pablo. «Control migratorio europeo en territorio africano: la omisión del carácter extraterritorial de las obligaciones de derechos humanos». SUR Revista Internacional de Derechos Humanos. Año 6, n. ${ }^{\circ} 10$, 2009: 189-216. Acceso: 01 de julio de 2017. http://www.corteidh.or.cr/tablas/r23746.pdf

Comité de Protección de los Derechos de todos los Trabajadores Migratorios y de sus Familias. Observación general $n .^{\circ} 2$ sobre los derechos de los trabajadores migratorios en situación irregular y de sus familiares. 28 de agosto de 2013, CMW/C/GC/2.

Gallagher, Anne T. y Fiona, David. The Internacional Law of Migrant Smuggling. New York: Cambridge University Press, 2014, 37.

Instituto de Democracia y Derechos Humanos de la Pontificia Universidad Católica del Perú (IDEHPUCP), Informe alternativo sobre Perú al Comité de protección de los Derechos de todos los Trabajadores Migratorios y de sus Familiares. 2017 P.12. Acceso: 13 de diciembre, 2017.

http://cdn01.pucp.education/idehpucp/wp-content/uploads/2017/09/11234252/11-09-final-informe-alternativo-al-comite-de-proteccion-trabajadores-migratorios.pdf

Luna Chávez, Gonzalo. «Tráfico ilícito de migrantes en frontera Tacna-Arica: causas, modalidades de captación, traslado, rutas y accidentes frecuentes». Ponencia realizada en el V Congreso Latinoamericano sobre Trata y Tráfico realizado en Lima el días 14 de julio de 2017.

Mac Gillivray, Jeremy y otros (coordinadores). «Manual de capacitación para operadores de justicia durante la investigación y el proceso penal en casos de trata de personas». Lima: IDEHPUCP/OIM, 2017.

Murillo, Juan Carlos. «Migración extracontinental en América Latina: algunas tendencias y consideraciones de protección internacional, 2010». Acceso: 12 febrero, 2018. http://www.acnur.org/t3/fileadmin/Documentos/BDL/2010/7720.pdf?view=1

Oficina de las Naciones Unidas Contra la Droga y el Delito, Ley modelo contra el tráfico ilícito de migrantes 2010. Acceso: 12 febrero, 2018. https://www.unodc.org/documents/human-trafficking/Model_Law_ SOM_S_ebook_V1052718.pdf

Oficina del Alto Comisionado de las Naciones Unidas para los Refugiados, Manual de Procedimientos y Criterios para Determinar la Condición de Refugiado en virtud de la Convención de 1951 y el Protocolo de 1967 sobre el Estatuto de los Refugiados 1992. Acceso: 12 febrero, 2018. http://www.acnur.org/t3/fileadmin/Documentos/BDL/2011/7575.pdf

Organización Internacional para las Migraciones. Fatal Journeys. Volume 2: «Identification and Tracing of Dead and Missing Migrants 2016». Acceso: 05 de julio, 2017. https://publications.iom.int/system/files/ fataljourneys_vol2.pdf

Van Liempt, Ilse y Sersli, Stephanie State. «Responses and Migrant Experiences with Human Smuggling: A Reality Check». Antipode, Vol. 45, n. ${ }^{\circ} 4$ (2013): 1029-1046.

Vasquez, Tania, Erika Busse y Lorena Izaguirre. Migración de población haitiana a Perú y su tránsito hacia Brasil desde el año 2010 (2015). Acceso: 05 de julio, 2017. http://repositorio.iep.org.pe/bitstream/IEP/11/1/ Vasquez_Migraciondepoblacion.pdf 


\section{Normas internas}

Decreto legislativo n. ${ }^{\circ} 1350$. Decreto de Migraciones Publicado en el Diario Oficial el Peruano, 7 de enero, 2017.

Decreto Supremo n. ${ }^{\circ}$ 007-2017-IN. Reglamento del Decreto Legislativo n. ${ }^{\circ} 1350$, Decreto Legislativo de Migraciones Publicado en el Diario Oficial el Peruano, 29 de enero, 2017.

Ley n. ${ }^{\circ}$ 28950. Ley contra la Trata de Personas y el Tráfico Ilícito de Migrantes. Publicado en el Diario Oficial el Peruano, 16 de enero, 2007.

Decreto supremo n. ${ }^{\circ}$ 007-2008-IN aprueban Reglamento de la Ley n. ${ }^{\circ} 28950$. Ley contra Trata de Personas y el Tráfico Ilícito de Migrantes Publicado en el Diario Oficial el Peruano, 30 de noviembre, 2008.

Decreto Supremo n. ${ }^{\circ} 001-2016-\mathrm{IN}$ que aprueba el Reglamento de la Ley n. ${ }^{\circ} 28950$. Ley contra la Trata de Personas y el Tráfico Ilícito de Migrantes, y crea la Comisión Multisectorial de naturaleza permanente contra la Trata de Personas y el Tráfico Ilícito de Migrantes. 